\title{
MENTEE PERCEPTIONS OF BENEFICENCE OF FACULTY-CENTRED ACADEMIC MENTORING: REFLECTIONS FROM A PILOT PROGRAMME
}

\author{
L. L. Phiri \\ Department of Psychology \\ University of Johannesburg \\ Johannesburg, South Africa \\ e-mail: lebop@uj.ac.za
}

\section{ABSTRACT}

There are three notable changes that have radically changed the landscape of higher education in South Africa (SA) over the past decade. These changes relate to access which is reflected in the growth of the student body, a movement towards free university education and a call for decolonisation of knowledge recently led by the \#FeesMustFall movement in 2015. Academic mentoring can be a reflexive praxis to some of the reported challenges that have been associated with formal and epistemological access in higher education in South Africa. This article draws on the findings of a two-year pilot project (2015 to 2016) that explored academic mentoring within the Faculty of Engineering and Building Studies at the University of Johannesburg (UJ), South Africa. The article reflects on mentees' perceptions of the benefits of academic mentoring. The uniqueness of the article is that it highlights the value of mentoring during the transition between the first year at university and subsequent senior years of the students' academic trajectory. A survey approach using an evaluation-based questionnaire was employed in a sample of 14 ( $n=$ 14) participants in the first to fourth years of study towards a Bachelor's degree in Engineering. The perspectives of mentees were examined in terms of their experiences of participation and perceived benefits of mentoring, both academic and psychosocial. Generally, a considerable number of mentees who participated in the programme saw academic and psychosocial benefits resulting from their participation. Findings provide key considerations in support of the expansion and continuity of academic mentoring programmes in the Faculty of Engineering and Building Studies and the University at large. Academic mentoring is beneficial to all the stakeholders involved if it is done correctly.

Keywords: academic mentoring, mentoring benefits, higher education, university, student support

\section{INTRODUCTION}

There are three specific changes that have arguably revolutionised the landscape of higher education in South Africa (SA) over the past decade. The first change involves growth in student numbers and greater diversity within the student body in terms of age, race, ethnic group and socio-economic status. The South African National Development Plan 2030 has projected 
a 30 per cent increase in widening formal access to the higher education system for students who wish to study at a university (Republic of South Africa 2012, 275). This means that access to higher education in South Africa is no longer exclusive to the elite but forms an accessible means by which ordinary citizens can better the conditions of their lives. The second change relates to a recent issue that was driven by the \#FeesMustFall student-led movement in South Africa in 2015, which speaks to student fees. The third change, which was also driven by the \#FeesMustFall movement, involves the call for decolonisation of knowledge. Resultantly, free university education for the poor is a feasible reality for South African universities (example, Badat 2016; Department of Higher Education and Training 2018,1) and, contentious as it is, a movement towards the decolonisation of curricula has begun (example, Council on Higher Education (CHE) 2017). Great as these milestones may be, on the other hand, they have been shown to come with numerous challenges (which are discussed in sections that follow). This is perhaps more accurate for the changes that have be associated with access (Du Preez, Steenkamp and Baard 2013; CHE 2013) as the other subsequent changes are more recent. The article discusses academic mentoring within the context of the challenges that have been associated with increases in the student body due state policies about access.

\section{Higher education challenges and mentoring}

Academic mentoring in higher education in South African can be seen as a reflexive praxis to some of the challenges associated with the aforementioned state policies regarding formal and epistemological access (Republic of South Africa 2012, 275). Paradoxically, while policies around access have evened the scale in promoting equality regarding access and participation in higher education in South Africa, the "opening up" of the doors to universities or other forms of higher education has been shown to come with unprecedented challenges related to student success at university. Regrettably, these challenges are intensified among under-prepared students from diverse backgrounds, and certainly by a tumultuous socio-economic and political climate (Du Preez et al. 2013; Van Zyl, Gravett and De Bruin 2012). Current literature maintains that the proliferation of student numbers over the years (a trend promising to continue) has created new challenges for universities. These include teaching larger classes, the presence of under-prepared students who may require additional assistance coping with university demands, limited teaching time, limited face-to-face contact with the lecturer and learning barriers attributable to the increase in student diversity (Andrews and Clark 2011; Du Preez et al. 2013; Fox, Stevenson, Connelly, Duff and Dunlop 2010).

It is within this context that issues of transition, retention and attrition have arisen and continue to arise, naturally raising pedagogical concerns. The responsibility of higher education 
institutions to make provisions for students' varied needs and to mitigate issues of dropout while providing value for money cannot be overstated. To a certain extent, such provisions have already been made. Some of the reported promising support programmes aimed at retention and minimisation of dropout include orientation programmes, academic counselling, career counselling, tutoring, first-year success courses, academic probation identification, study-skills programmes and academic revision programmes (Habley, Bloom and Robbins 2012). An additional provision is mentoring. Mentoring as a concept is not at all new. Whether through serendipity (organic development between mentor and mentee) or by design (a formal programme), mentoring has almost always been shown to have a variety of positive gains, both psychological and academic, for both the mentee and the mentor (Andrews and Clark 2011). A more detailed explanation of mentoring is provided later in the article.

\section{Individual student challenges}

On an individual level, students around the world face a number of challenges. Arguably, being a student today may be more difficult than ever before. On a personal level, students experience numerous challenges including financial issues, academic stress, learning issues, graduate unemployment and relationship issues (Balu 2014; CHE 2013, 55; Dampier 2015). Additionally, parents frequently lack tertiary education and university experience and cannot help prepare students for such demands. In the case of the University of Johannesburg (UJ), over 60 per cent of the student population are first generation university entrants (University of Johannesburg Annual Report 2016, 265). This idea is supported by Jiang and Tam (2015) in a recent study, who report that students from more educated families have better chances of success in higher education than those from significantly less educated family backgrounds. Left unattended, these individual challenges, together with the academic challenges of higher education, may lead to disastrous outcomes for the students involved.

Mentorship programmes in higher education can be designed to provide support to students not only in the first year of university, but also throughout their academic trajectories until completion of their studies, or as they make the transition into postgraduate studies or formal employment. A discussion of the psychosocial, academic and professional gains associated with mentoring is provided in subsequent sections of the article. The current article reflects and reports on mentees' perceived beneficence of mentoring received through a facultybased pilot programme. This programme provided academic mentoring within the Faculty of Engineering and Building Studies (FEBE) at UJ. The uniqueness of the study is that it highlights the value of mentoring during the transition between the first year of university and subsequent senior years of the students' academic trajectories. 


\section{Objectives of the study}

The study seeks to explore students' perceived value of academic mentoring. Specifically, the study aimed to answer the following research questions:

1. What are mentees' perceived benefits of academic mentoring?

2. Do students regard academic mentoring as contributory to academic success?

\section{Context of the study}

The study took place at UJ in South Africa within FEBE. UJ is home to more than 50000 students within nine faculties, spread throughout four campuses. In response to the South African national transformation agenda, the University's black student body has grown to 92,5 per cent. Thirty-one (31) per cent of the 92,5 per cent come from schools from the poor communities of South Africa (University of Johannesburg Annual Report 2016, 33). In 2017, UJ made its first entry as the only African university to be ranked in the Quacquarelli Symonds (QS) Top 100 under 50 (which ranks the world's top 100 institutions under 50 years of age) in the QS World University Rankings. As with many other universities around the world, issues of attrition and dropout are not uncommon at UJ. As a result, the University established the tutor programme, which is one of the formal support programmes aimed at providing academic support and mitigating potential difficulties associated with the growing student body. UJ has the largest tutor programme in South Africa with approximately 3500 tutors involved (University of Johannesburg Annual Report 2016, 45). Other less formal support programmes include the student residence advisory that is run by the University's residences programme, as well as intermittent needs-based student mentoring programmes.

\section{LITERATURE REVIEW}

\section{Defining mentoring}

The concept of mentoring has gained a great deal of currency over the past three decades, particularly in its association with student success. Mentoring is well established as a support strategy that has been linked with academic, social and emotional benefits for its participants (examples include Crisp and Cruz 2009; Du Preez et al. 2013; Tinto 1975. It is reported that the concept of mentoring goes as far back as Greek mythology. It is said that Odysseus left his household, and his son in particular, in the trusted care of his friend Mentor (Anderson and Shannon 1988). Hence, the term "mentor" has come to be associated with caring roles such as 
those occupied by friends, teachers, counsellors and/or advisors.

This section will review the definition of mentoring as reported in the literature. It should be noted that the literature is full of various definitions of the term "mentoring". To be precise, there are over 50 definitions of "mentoring" that have been identified in the literature (Crisp and Cruz 2009). Each definition has been constructed for a specific purpose and with diverse understandings of who or what is meant by "mentor", rendering the term difficult to define. Part of the difficulty experienced in the definition of "mentoring" lies in the seemingly interchangeable use of various related terms as found in the literature. Examples of these terms include "peer mentoring", "guiding”, "peer buddy", "tutoring”, "assisted learning”, “coaching” and "sponsoring" (Abiddin and Hassan 2012; Andrews and Clark 2011; Cripand Cruz 2009; Du Preez et al. 2013). Agreeably, this assortment of terms reflects, to some extent, the intricacies and nuances inherent in the role of a mentor, while simultaneously contributing to the disagreement evident among scholars.

The diverse array of definitions reveals a common undertone and understandings of what is meant by "mentoring". Specifically, mentoring involves three primary elements, namely supporting, helping and transferring knowledge. Just to look at a few examples and beginning with a more conservative definition, Campbell and Campbell $(1997,727)$ refer to mentoring as a "situation in which a more experienced member of an organization maintains a relationship with a less experienced, often new member of the organization and provides information, support, and guidance so as to enhance the less experienced member's chances of success in the organization and beyond". Hall's $(2002,147)$ definition of mentoring, as an "intentional relationship focused on developing self of relatively unseasoned protégé through dialogue and reflection", conveys the element of offering help and, to an extent, the transfer of knowledge. What is particularly emphasised here is that the primary objective of the mentoring relationship is to cultivate the learning potential of the mentee by sharing knowledge and expertise. The third element of mentoring, namely knowledge transfer, is emphasised by Gibbons (2004) who defines mentoring as "a protected relationship in which learning and experimentation can occur, potential skills can be developed, and in which results can be measured in terms of competence gained rather than curricular territory covered". A definition that is perhaps more useful and applicable to educational settings is provided by Harmon $(2006,56)$, who defines peer mentoring as a type of peer education involving more mature or more competent students serving as role models to inexperienced or less capable students. Importantly, a mentor is a person who has walked the same path as those wishing to follow suit.

It should be noted that because of their inherent similarities, terms such as "mentoring", "peer mentoring" and "academic mentoring" are used interchangeably in subsequent literature 
sections of the article. For the purposes of this article, the term "academic mentoring" is adopted. The article adopts the term "academic mentoring" primarily because of the specific academic focus and design of the mentoring programme involved. Details and objectives of the mentoring programme in question are provided in the methodology section of the article.

Additionally, Vygotsky's theory $(1978,86)$ is particularly useful in capturing the pedagogical value inherent in peer learning within the context of academic mentoring. Vygotsky's $(1978,86)$ concept of the "zone of proximal development" represents the idea that social interaction is essential to development - i.e., that student learning is encouraged and facilitated by interaction with more capable peers. Vygotsky $(1978,86)$ defined the zone of proximal development as "the distance between the actual development level as determined by independent problem-solving and the level of potential development as determined through problem-solving under adult guidance or collaboration with a more capable peer”. Imbedded in the definition is the premise that learning and knowledge develop through social interactions and transfer between students in a manner that is qualitatively different from that taking place in formal learning structures such as lecture halls. More important is the idea that this particular kind of transfer and learning would not occur outside of the environment of peer learning. Smith (2009) maintains that mentors can serve as socialisation agents; through sharing their knowledge and experiences of the university, they can assist other students in learning to manage its demands. This article proposes the idea that academic mentoring can be a combination of both pastoral and academic support.

\section{Characteristics of a mentor}

Ideas of what constitutes a successful mentor depend upon the context of the community of practice concerned. When hiring students to fulfil the role of mentors, one must consider the extent to which the mentees would be able to identify with the peer mentors and regard them as potential role models. Traditionally, peer mentors are based within the residential setting and are known as "residence assistants" or "advisors", popularly known as RAs (Terrion and Leonard 2007). These student peers provide support in terms of the transition into university, academic success and interpersonal development of individual students. While responsibilities and context vary widely, the fundamental role of the peer mentor concerns having directed interaction with target students with the aim of transferring knowledge and experience. Therefore, where possible, the peer mentor should have characteristics that are shared with the target group so that the students (mentees) can identify with him or her. Such common characteristics include, inter alia, gender, race, age (especially considering the gap in age between the mentor and mentee), level of study (considering how advanced and/or experienced 
the mentor and mentee are in relation to each other) and economic background (Terrion and Leonard 2007). Shared characteristics such as these render the mentor more approachable and relatable, which, to some extent, can be considered key to the success of the mentoring relationship.

In the context of higher education, Terrion and Leonard (2007) argue that programmes relying on mentors for teaching assistance or supplementary instruction would require greater academic and teaching experience on the part of the mentors. In this case, students who are more senior and academically strong would have a good fit. On the other hand, mentors who are needed for student orientation and for assisting first-year students to transition into the university would need a different set of characteristics. Here, a junior or second-year student would be ideal because of their readily accessible memories of first year and proximity to transition issues. Academic success is arguably the primary goal of mentoring programmes; therefore, peer mentors should set the example and be outstanding students who also have experience with student development issues. In addition, students who are familiar with issues pertaining to campus and student life and who are involved in campus community activities would contribute significantly towards the psychosocial aspects of the peer mentor role. Terrion and Leonard (2007) argue that when compared with peer tutors, mentors are better candidates for providing psychosocial support by showing friendship, offering emotional support and providing personal feedback. The section that follows summarises the perceived benefits of mentoring from the perspectives of the institution, the mentee and the mentor.

\section{Benefits of mentoring for the institution}

It is well known that academic mentoring has grown exponentially and is practised in most universities and other institutions of higher learning as a support and retention strategy. Ekechuku and Horsfall (2015) maintain that academic mentoring in higher education can be a unique monitoring exercise, one that is specifically designed to promote students' intellectual, academic and personal development. The university benefits from academic mentoring in several ways as mentoring facilitates identification of at-risk students (Robinson and Niemer 2010), better grades (Dioso-Henson 2012), increased student engagement (Clark et al. 2013), increased retention and decreased rates of attrition and favourable student experience of the university (Bettinger and Baker 2014; Fox and Stevenson 2006; Sneyers and De Witte 2017; Tinto 1975). Such benefits could arguably yield a renewed dedication to the university.

\section{Mentoring benefits for the mentee}

Naturally, the enterprise of any mentoring programme is to promote the success of the mentees. 
There seems to be limited literature regarding mentoring programmes and their benefits for students beyond the first year of their studies. Therefore, the discussion provided below mainly considers students in the first year of university. The following benefits have long been associated with peer mentoring programmes: improved sense of belonging, smoother transition into the university, reduced rates of attrition, improved interpersonal relationships and better study and time management skills (Bettinger and Baker 2014; Glaser, Hall and Halperin 2006; Sneyers and De Witte 2017). Importantly, feeling that one does not belong is undisputed in the literature as one of the many reasons behind significant dropout rates in the first year of university globally (Tinto 1975). According to students' reports, benefits associated with having a mentor can be summarised as follows: improved self-confidence, the promotion of friendships and networks, enhanced capacity to adjust to university culture and a new "university student" identity, support in managing personal problems and non-study related matters and assistance with difficult modules (Bettinger and Baker 2014; Du Preez et al. 2013; Fox and Stevenson 2006; Sneyers and De Witte 2017).

The prevailing idea in the literature is that peer mentoring is useful for providing psychosocial support for new students while peer tutoring provides academic support. The positive correlation between tutoring and academic success has been sufficiently studied. Examples from the literature include Andrews and Clark (2011), Fox and Stevenson (2006) and Tinto (1975). The idea presented in this article is that academic mentoring can be a unique combination of both peer tutoring and peer mentoring. However, both mentoring and tutoring relationships within a learning context are susceptible to difficulties involving the fit between participants. A poor fit between a mentor and mentee or between a tutor and tutee will compromise the learning process. For instance, partnering students who are not academically strong with underperforming "mentors" will not lead to the desired outcomes (Andrews and Clark 2011). As such, the mentors' academic strength is of paramount importance to the success of the mentor-mentee relationship. Difficulties tend to occur when students lack confidence in and do not adequately trust their mentors (Fox and Stephenson 2006).

\section{Benefits of mentoring for the mentor}

The benefits of mentoring for mentors have not received the same attention in the literature as mentee benefits. The potential for reciprocity within the mentor-mentee relationship is arguably one of the most noteworthy benefits of mentoring as reported by mentors (Beltman and Schaeben 2012; Irby 2014). Some of the reported advantages of mentoring from the mentors' perspective include the positive feelings resulting from acts of altruism, a greater sense of awareness, the opportunity to network and increased appreciation for diversity. This is 
corroborated by Peck (2011), who found that a strong sense of connection to others, personal development and increased appreciation for diversity are reported as gains by mentors. In their study on an institution-wide peer mentoring programme, Beltman and Schaeben (2012) suggest that benefits for mentors can be summarised as falling within four categories, namely altruistic benefits (characterised by fulfilment from the joy of serving others), cognitive benefits (for example, communication and social skills), social benefits (characterised by the formation of new networks and friendships) and lastly personal growth (characterised by empathy and a sense of duty). Notably, mentor-mentee relationships do not always result in the positive outcomes portrayed by much of the literature just reviewed. Issues of power, gender, class, race and sexual orientation may influence the dynamics and workings of the relationship and ultimately the success of the relationship and the programme at large.

\section{METHODOLOGY}

\section{Programme and project partners}

The programme was internally organised and introduced within FEBE at UJ in the years 2015 to 2016. The programme involved a collaboration between the Gauteng Department of Infrastructure Development (GDID), FEBE at UJ and the Academic Development Centre (ADC) at UJ. The GDID provided financial aid for students that were enrolled for an engineering qualification at $\mathrm{UJ}$ as well as remuneration for the mentor for the duration of the programme. A representative of FEBE was primarily responsible for identifying the qualifying students and for monitoring the students' academic progress. The ADC at UJ is a support centre aimed at providing academic support to students. In this context, a representative of ADC was responsible for the training and development of the mentor. The aim of the mentoring programme was to provide bursary recipients with support in the form of academic and professional skills development. Examples of the skills developed included time management, development of a study schedule, creative study techniques, note-making strategies, examtaking strategies and professional development.

\section{Participants}

Participants $(n=14)$ of the study were bursary recipients in their first to fourth years of study towards a bachelor's degree in Engineering at UJ. Fifty per cent (seven) of the participants were first-year students, 21,6 per cent (three) were in their second year of studies, 14,2 per cent (two) were third-year students and lastly, 14,2 per cent (two) were in their fourth and final year of studies. At the time of the pilot programme, only 18 students were identified as recipients of 
the bursary and were invited to participate in the programme. All 18 mentees were invited to complete the questionnaires, but only 14 responded. The mentees gave consent for their data to be used for research purposes.

\section{Programme structure}

\section{Mentor recruitments}

UJ students interested in mentoring were recruited via a formal advertisement and encouraged to send their applications to the mentor coordinator (a representative of ADC). Applications had to include evidence of academic strength (in the form of an academic transcript), a motivational letter indicating reasons for wanting to be a mentor, a description of perceived potential contribution to the programme, an indication of experience related to student support and a traceable reference. Through a selection process involving the mentor coordinator and other staff members of ADC, suitable candidates were shortlisted and invited to participate in an interview process where the successful mentor was ultimately chosen. For this pilot programme, the mentor was a UJ master's student in Engineering.

\section{Mentor training and development}

The mentor was trained and prepared for his role through a centrally-managed training workshop that was run under the leadership of the mentor coordinator. The training workshop was conducted over two days during orientation week. The content covered in the training included an overview of the programme with a strong emphasis on student development and transition into university, the role of a mentor, academic skills and group and conflict management techniques. Additionally, issues surrounding cultural diversity and sensitivity were discussed. Lastly, the mentor was familiarised with the key campus resources offering different kinds of support to students, such as the library, psychological services and financial aid services. The mentor was then provided with a training package that included a booklet containing guidelines for mentoring and additional handouts and resources for referral. The mentor was rewarded for his services with a monthly stipend and a certificate of service received at the end of the academic year. Continued development was provided through regular meetings between the mentor and the mentor coordinator who ran the programme.

\section{The role of the mentor}

The mentoring programme was designed so that participation on the part of mentees was encouraged but not compulsory. The mentor was responsible for overseeing the mentees' 
development by means of structured, bi-weekly, one-on-one meetings and group meetings. Typically, as a way to induct the mentees into the programme, the mentor was required to schedule a meet-and-greet group meeting with all the mentees in the first week of the commencement of lectures. This usually took place about one or two weeks after the orientation period. The purpose of the meet-and-greet group meeting was to introduce the mentees to the mentor, communicate the purpose of the programme and outline the responsibilities of each stakeholder in the mentoring programme. It was then left to the mentor's prerogative to schedule one-on-one and group meetings according to the students' schedules. The duration of the one-on-one meetings was one hour. The duration of the group meetings was between one and two hours, depending on the topic. The mentor's role during the structured one-on-one meetings involved monitoring the students' (mentees') progress with their studies, identifying issues (such as personal or academic issues) and applying appropriate interventions as required at the time (for example, developing a study schedule or assisting the student with a difficult concept). In accordance with the mentor's discernment, the group meetings were organised around common academic issues experienced and identified by the mentees, for example, testtaking skills.

\section{Data collection}

\section{The questionnaire}

A survey method was adopted for the current study (Fowler 2013). In order to gain an understanding of the students' (mentees') perceived benefits of the academic mentoring programme, the researcher developed an online mentee-mentor evaluation questionnaire. The aim of the questionnaire was to solicit the mentees' perceptions regarding their experiences with mentoring. The questionnaire comprised of 14 items divided into two sections: nine Likert (4-point) scale questions and five open-ended questions. Areas that were assessed by the questionnaire included satisfaction with the mentor, academic skills learned, effectiveness of the one-on-one meetings, perceived benefits of having a mentor, least favourite aspects of being part of a mentoring programme and suggested areas for improvement.

\section{Procedures and analysis}

The researcher circulated the questionnaire via email in mid-October 2016. Students were given a period of two weeks to complete the questionnaires and a few reminders thereafter. Only 14 of the 18 questionnaires were returned fully completed. The data contained in the questionnaires were transferred to Excel $(n=14)$. The open-ended sections of the questionnaire were analysed 
using thematic analysis (Lapadat 2010). The quantitative items are expressed in percentages separately from the qualitative items. The results are presented below in two separate sections.

\section{FINDINGS AND DISCUSSION}

\section{Mentee perceived benefits of academic mentoring}

Results are summarised in the tables below. Table 1 shows the summarised percentages of mentees' perceived benefits per item and Table 2 summarises qualitative benefits of participating in an academic mentoring programme. Generally, about 86 per cent of the mentees were satisfied with the mentor's helpfulness. Only 14 per cent of the mentees felt that the mentor was not helpful. Note the positive associations between mentees' confidence and trust in the mentor and the success of the mentoring relationship; trust and confidence in the mentor are clearly essential elements of the relationship. The mentor's academic strength and the mentees' perceptions of the effectiveness of the mentor are critical to a successful mentoring relationship. Conversely, a lack of trust and confidence has been associated with failed mentoring programmes (Fox and Stephenson 2006).

Table 1: Mentee perceived benefits of academic mentoring $(n=14)$

\begin{tabular}{|l|c|}
\hline \multicolumn{1}{|c|}{ Item } & Percentage \\
\hline My mentor was very helpful. & 86 \\
\hline My mentor demonstrated reasonable concern/interest in my development. & 93 \\
\hline I have gained new skills from my mentor. & 79 \\
\hline The one-on-one meetings were helpful. & 78 \\
\hline My mentor assisted me with the modules I struggled with. & 79 \\
\hline Overall, having a mentor assisted me in improving my marks. & 86 \\
\hline The percentages are calculated out of 100\% per item hence together they add up to more than $100 \%$. \\
\hline
\end{tabular}

Ninety-three (93) per cent of the mentees reported that the mentor had demonstrated reasonable concern for their development and only 7 per cent felt otherwise. This is interesting because it means that the 14 per cent who felt that the mentor was not helpful nevertheless agreed that the mentor had shown concern for their development. This finding agrees with several studies reporting that mentors' ability to show concern for mentees' personal development is particularly significant to mentees (Andrews and Clark 2011). About 79 per cent of the mentees felt they had gained a combination of skills from having a mentor. This item is later followed up in the qualitative section of the questionnaire where mentees were asked to list combinations of academic skills gained through participation in the programme (see Table 2). Seventy-nine (79) per cent of the mentees reported that the mentor had assisted with the modules they 
struggled with while 21 per cent felt otherwise. This is particularly noteworthy and consistent with literature in that assistance with difficult modules is one of the reasons that students ask for mentors; it is equally reported as a gain by mentors (Andrews and Clark 2011; Du Preez et al. 2013). About 86 per cent of the mentees reported that having a mentor had assisted them in improving their academic performance while 14 per cent did not agree. This is also evidenced and discussed in the open-ended section where mentees reported improved marks as part of their gains from academic mentoring (see Table 2).

Table 2: Qualitative benefits of academic mentoring

\begin{tabular}{|c|c|}
\hline Item & Responses \\
\hline In what ways has mentoring been beneficial to you? & $\begin{array}{l}\text { - Confidence } \\
\text { - Support } \\
\text { - Belonging } \\
\text { - Appreciation of diversity } \\
\text { - Networking } \\
\text { - Improved academics }\end{array}$ \\
\hline $\begin{array}{l}\text { List some of the activities or helpful solutions you learned } \\
\text { and applied while working with your mentor which you } \\
\text { continue to apply in your studies. }\end{array}$ & $\begin{array}{l}\text { - Creative study techniques } \\
\text { - Exam preparation techniques } \\
\text { - Organisation and time management techniques } \\
\text { - Methods for managing stress }\end{array}$ \\
\hline What did you not like about academic mentoring? & $\begin{array}{l}\text { - Limited number of mentors } \\
\text { - Unnecessary meetings } \\
\text { - Inconvenient meeting locations } \\
\text { - Prescriptive mentors }\end{array}$ \\
\hline $\begin{array}{l}\text { What do you think we should change or do differently in } \\
\text { the future? }\end{array}$ & $\begin{array}{l}\text { - More discipline-specific mentors } \\
\text { - Flexible meeting times } \\
\text { - Convenient meeting locations } \\
\text { - More assessment preparation }\end{array}$ \\
\hline
\end{tabular}

The qualitative responses regarding mentees' perceived benefits can be classified into two groups, namely psychosocial benefits and academic benefits. Under psychosocial benefits, as expected, mentees reported that they had gained more confidence in their ability to navigate university challenges. Mentees also reported feeling supported and having an increased sense of belonging as part of the benefits of academic mentoring. This is summarised by one student's response:

"I really loved that there was someone who was there to support me and help me with anything from study methods and other resources on campus that I didn't know about. This gave me a lot of confidence that I can do this and that I fit and I am not just a number."

As expected, responses of this kind were more common among first and second-year students in the programme than among more senior students. This finding is consistent with the literature (Bettinger and Baker 2014; Sneyers and De Witte 2017; Tinto 1975) which holds that feelings of support and belonging within the academy may help counter feelings of alienation. As a result, students are more likely to stay the course of their academic trajectory. On the other 
hand, feelings of not belonging or of not being unsupported have been linked with higher dropout rates among students, particularly first and second-year students. As a final point under the heading of psychosocial benefits, mentees reported that opportunities for networking and an increased appreciation for diversity were gains derived from academic mentoring. As an example, consider this student's response:

"You get to interact with people from different backgrounds and study fields who also experience similar challenges of the university as I do. We are so different, we are even at different levels but we are all in the same boat."

As was expected, the opportunity to make friends and build networks was reported as a gain. Other studies have reported similar findings (for example, consider Andrews and Clark 2011; Du Preez et al. 2013; Tinto 1975). However, a rather unexpected finding relates to issues of diversity. The expectation would have been that an awareness of and appreciation for diversity would be considered a greater gain for the mentor than for the mentees. This is in light of literature (Beltman and Schaeben 2012) highlighting these benefits as more significant to mentors than to mentees. With hindsight, it is not surprising that mentees and mentors reported similar perceptions regarding the benefits of mentoring. This is in part due to the reciprocal nature of the mentor-mentee relationship. The mentees also spoke favourably of the academic benefits experienced during the mentoring programme; these formed the second group of benefits considered. Mentees reported that learning creative study techniques as well as developing skills for exam preparation, organisation and time management and for managing stress were highlights of the academic skills training offered in the programme. One student's response summarises this point:

"We went through a number of studying methods of how to approach problems or questions based on a specific module and what to expect in exam questions. He also helped me with my time management and how to manage academic stress especially during exams."

This is consistent with favourable reports from the literature regarding benefits of mentoring programmes that have a specific focus on academic success (Terrion and Leonard 2007). This finding is also significant from the perspective of programme evaluation as the transfer of academic skills formed a secondary goal of the programme.

The third section of open-ended questions asked the mentees to list their least favourite aspects of academic mentoring as experienced in the programme. Most mentees reported the limited number of mentors, unnecessary one-on-one meetings, inconvenient meeting locations and prescriptive mentors as their least favoured aspects of the mentoring programme. One 
student's response summarises the undesirable element of a prescriptive mentor: "I dreaded meeting up with my mentor, judgement for not doing things the way he wants them".

In addition, the mentees made recommendations for more discipline-specific mentors, fewer meetings and more convenient meeting locations. These recommendations were expected as at the time of the programme only one mentor was assigned to 18 students who were at different levels of study and majoring in different areas. At the time of the programme, the mentor was a master's student in Engineering. Given the diversity of majors studied by the mentees, the mentor's ability to assist with various module-specific challenges would vary. It is agreed that the mentees would have benefited greatly from having access to a number of mentors who were focused on specific disciplines. The issues of excessive meetings and inconvenient meeting locations as raised by the mentees were also expected. At the time of the pilot programme, it was suggested that two one-on-one meetings per month should be the minimum. However, it is not uncommon for some students to be more adept at managing university challenges, and such students would dismiss the need for frequent meetings. Further, as FEBE was facilitating the programme, one of the FEBE laboratories was used as the primary location for the one-on-one meetings. Alternatively, the mentor would use the library to conduct the one-on-one meetings. From the open-ended section of the questionnaire, it emerged that mentees experienced these locations as less intimate and less comfortable. It should be noted that due to growing numbers within the student body, the limited availability of suitable venues presents a challenge at the University, and likely at most universities in South Africa. Most of the smaller venues that would have otherwise been used as alternative meeting venues for mentoring are used for formal tutorials. Understandably, these tutorials are prioritised by university management as they represent a formal support programme accompanying formal lectures. More informal initiatives are required to improvise and make do with less suitable locations.

\section{LIMITATIONS}

A few caveats to the study require consideration. First, there is the small sample size of the study. Because of the small sample, the findings cannot be generalised beyond the setting of the specific faculty and institution in question. The second limitation concerns the self-reporting nature of the questionnaire used in the study. Given the subjective nature of self-reports, one cannot ignore the potential influence of social desirability effects and memory bias.

\section{CONCLUSIONS}

The study set out to reflect on mentees' perceived benefits of participating in an academic- 
focused mentoring programme. Generally, a considerable number of mentees who participated in the programme saw academic and psychosocial benefits resulting from their participation. They were also able to improve their academic performance as a result. Although at the time of the pilot, the programme was not aimed at assessing direct correlations between the mentoring programme and students' specific grades, feedback provided by the mentees indicates that having a mentor contributed positively to their academic performance. Notably, a small number of mentees did not see any benefit from participation in the programme. To some extent, the perceived outcome of the mentor-mentee dynamism is informed by the perceptions of the individuals whom the programme is designed to benefit. Therefore, the number of benefits and the degree of satisfaction reported by the primary recipients of the programme, i.e., the mentees, attests to the success of the mentoring programme. Lastly, it would be worthwhile for future research efforts to study the benefits of mentoring from the perspective of the mentor, given the reciprocal nature of the relationship. Further, given the abundance of evidence regarding beneficence of mentoring for students in the first year of study at university, and the lack of research concerning later years, research exploring mentoring in the more senior years of studies would be valuable.

\section{REFERENCES}

Anderson, E. M. and A. L. Shannon. 1988. Toward a conceptualization of mentoring. Journal of Teacher Education 39: 38-42.

Andrews, J. and R. Clark. 2011. Peer mentoring works! How peer mentoring enhances student success in higher education. Aston University, report.

Abiddin, N. Z. and A. Hassan. 2012. A review of effective mentoring practices for mentees' development. Journal of Studies in Education 2(1): 72-89.

Badat, S. 2015. Deciphering the meanings and explaining the South African higher education student protests of 2015-2016. Pax Academica (1)2: 71-106.

Balu, L. 2014. Importance of mentoring in higher education. Journal of Education and Practice 34(5): $65-68$

Beltman, S. and M. Schaeben. 2012. Institution-wide peer mentoring: Benefits for mentors. The International Journal of the First Year in Higher Education 3(2): 33-44.

Bettinger, E. and R. Baker. 2014. "The effects of student coaching: An evaluation of randomized experiment in student advising." Education Evaluation and Policy Analysis 36(1): 3-19.

Campbell, T. A. and D. E. Campbell. 1997. Faculty/student mentor programs: Effects on academic performance and retention. Research in Higher Education 38(6): 727-742.

CHE see Council on Higher Education

Clark, R., J. Andrews and P. Gorman. 2013. Tackling Transition: The value of peer mentoring. Widening Participation and Lifelong Learning 14(1): 57-75.

Crisp, G. and I. Cruz. 2009. Mentoring college students: A critical review of the literature between 1990 and 2007. Research in Higher Education 50(6): 525-545.

Council on Higher Education. 2013. A proposal for undergraduate curriculum reform in South Africa: The case for a flexible curriculum structure. Pretoria: CHE Publication. 
Council on Higher Education. 2017. Decolonising the curriculum. Pretoria: CHE Publication.

Dampier, G. 2015. A qualitative study of the reasons for students dropped out in 2015. Presentation at the FYE UJ Strategic Committee. http://www.sanrc.co.za/FYEGoodPracticesGuide2.pdf (Accessed 3 February 2018).

Department of Higher Education and Training. 2018. Media briefing input on subsidised free higher education for poor and working-class students, 4 January 2018. http://www.dhet.gov.za/Site Assets/Media/Statements/2018/Media\%20Briefing\%20Input\%20on\%20Subsidised $\% 20$ Free $\% 20$ Higher\%20Education $\% 20$ for $\% 20$ Poor $\% 20 \% 20$ and $\% 20$ Working\%20Class $\% 20$ Students $\% 20 \mathrm{FIN}$ AL.pdf (Accessed 17 July 2018).

Dioso-Henson, L. 2012. The effect of reciprocal peer tutoring and non-reciprocal peer tutoring on the performance of students in college physics. Research in Education 87(1): 34-49.

Du Preez, R., L. P. Steenkamp and R. S. Baard. 2013. An investigation into a peer module mentoring programme in economic and management sciences. International Business and Economics Research Journal 12(10): 1225-1238.

Ekechuku, R. O. and M. N. Horsfall. 2015. Academic mentoring in higher education: a strategy to quality assurance in teacher education in Nigeria. European Journal of Research and Reflection in Educational Sciences 3(2): 34-45.

Habley, W. R., J. L. Bloom and S. Robbins. 2012. Increasing persistence: Research-based strategies for college student success. San Francisco, CA: Jossey-Bass.

Fox, A. and L. Stevenson. 2006. "Exploring the effectiveness of peer mentoring of accounting and finance students in higher education". Accounting Education: An International Journal 15(2): 189-202.

Fox, A., L. Stevenson, P. Connelly, A. Duff and A. Dunlop. 2010. Peer-mentoring undergraduate accounting students: The influence on approaches to learning and academic performance. Active Learning in Higher Education 11(2): 145-156.

Fowler, F. J. 2013. Survey research methods. Thousand Oaks, CA: Sage publications

Gibbons, S. K. 2004. Mentoring in business and industry: The need for a phenomenological perspective. Mentoring and Tutoring 12(2): 259-275.

Glaser, N., R. Hall and S. Halperin. 2006. Students supporting students: The effects of peer mentoring on the experiences of first year university students. Journal of the Australia and New Zealand Student Services Association 27: 4-17.

Hall, D. T. 2002. Careers in and out of Organization. Thousand Oaks, CA: Sage Publications.

Harmon, B. V. 2006. A qualitative study of the learning processes and outcomes associated with students who serve as peer mentors. Journal of the First-Year Experience and Students in Transition 18(2): 53-82.

Irby, B. J. 2014. Editor's overview: A 20-year content review of research on the topic of developmental mentoring relationships. Mentoring and Tutoring: Partnership in Learning 22(3): 181-189. doi:10.1080/13611267.2014.929329.

Jiang, J. and T. Tam. 2015. Rising class inequality of higher education during rapid college expansion in China, 1988-2002. Working Paper 5. http://www.researchcghe.org/perch/resources/ publications/wp5.pdf (Accessed 5 March 2018).

Kirigha, K.A. and P. Neema-Abboki. 2010. Developing a web explicit research strategy theory in African Universities: A cross-comparison of specific regional efforts through an analysis of research web pages. Research in Higher Education Journal 9. http://cees.mak.ac.ug/sites/ default/files/10552-1.pdf (Accessed 10 February 2018).

Lapadat, J. 2010. Thematic analysis. In Encyclopedia of Case Study Research, ed. A. J. Mills, G. Durepos and E. Wiebe, 926-928. Thousand Oaks, CA: SAGE Publications, Inc.

Peck, A. 2011. Peer involvement advisors improve first-year student engagement and retention. About Campus 16(3): 22-25. 
Republic of South Africa. 2012. National Development Plan. Our future - Make it work. http://www. info.gov.za/view/DynamicAction?pageid=623and myID=348761 (Accessed 18 March 2018).

Smith, B. 2009. Mentoring programs: The great hope or great hype? ASHE/Lumina Policy Briefs and Critical Essays, No. 7. University of St. Thomas. https://files.eric.ed.gov/fulltext/ED530577.pdf (Accessed 22 February 2018).

Robinson, E. and L. Niemer. 2010. A peer mentor tutor program for academic success in nursing. Nursing Education Perspectives 31(5): 286-289.

Sneyers, E. and K. De Witte. 2017. Interventions in higher education and their effect on student success: A meta-analysis. Educational Review. DOI:10.1080/00131911.2017.1300874 (Accessed 22 August 2017).

Tinto, V. 1975. Dropout from higher education: A theoretical synthesis of recent research. Review of Educational Research 45: 89-125.

Terrion, J. and D. Leonard. 2007. A taxonomy of the characteristics of student peer mentors in higher education: Findings from a literature review. Mentoring and Tutoring: Partnership in Learning 15(2): 149-164.

University of Johannesburg Annual Report. 2016. University of Johannesburg. https://www.uj.ac.za/ about/Documents/Annual\%20reports/UJ_AnnualReport2016_DHE__ Digital\%20(final\%2027 \%20June\%202017).pdf (Accessed 30 March 2018).

Van Zyl, A., S. Gravett and G. P. de Bruin. 2012. To what extent do pre-entry attribute predict first year student academic performance in South African context? South African Journal of Higher Education 26(5): 1095-1111.

Vygotsky, L. S. 1978. Mind in society. Cambridge, MA: Havard University Press. 